\title{
Um sociólogo em mangas de camisa: Guerreiro Ramos e a luta pelo Brasil
}

\section{A sociologist in shirt sleeves: Guerreiro Ramos and the struggle for Brazil}

\section{angelo Remedio neto*}

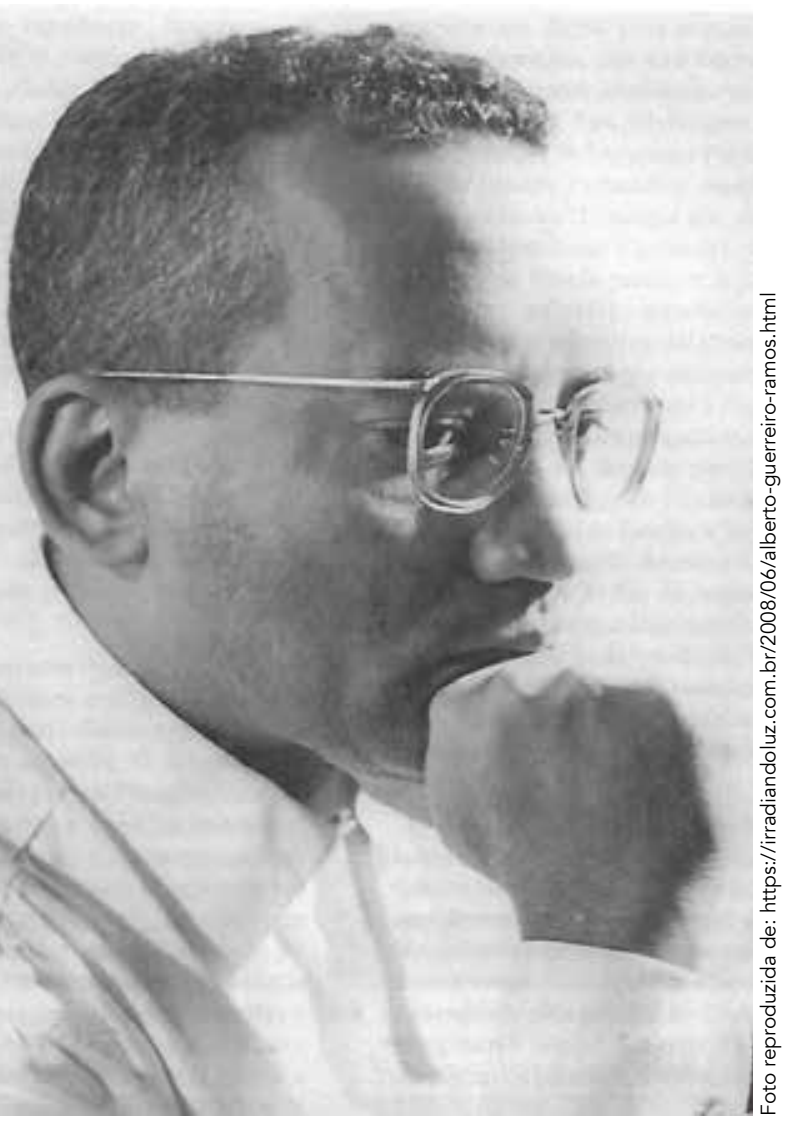

Para falar uma linguagem hegeliana, neguei a ciência do gabinete no gabinete, ou, ainda, neguei a sociologia de gabinete fazendo sociologia de gabinete, a despeito do caráter concreto que tiveram sempre as minhas cogitações. Mas, agora, me é oferecida a feliz oportunidade de não me enquistar ou cristalizar numa posição, de dar um passo adiante e de negar a sociologia de gabinete fora do gabinete, isto é, na prática social, "pensando com as mãos", confundindo-me com as aspirações, os movimentos dos trabalhadores e dos estudantes. Alberto Guerreiro Ramos, 1959 


\section{RESUMO}

Guerreiro Ramos está perfilado entre os mais proeminentes sociólogos brasileiros do século XX, dando considerável contribuição à construção de uma sociologia autêntica e inovadora que teria por objetivo último resolver problemas concretos do desenvolvimento político e social do Brasil. Faremos uma análise do desenvolvimento teórico de Guerreiro Ramos desde a elaboração da metodologia da redução sociológica, na década de 1950, até seus trabalhos de cunho mais eminentemente político, já na década de 1960. Por meio da metodologia calcada nos estudos do pensamento político brasileiro, poderemos ver a formação da teoria social de Guerreiro e sua rejeição a fórmulas prontas, desenvolvidas em outros países, para solucionar problemas nacionais. Nessa polêmica, a redução sociológica tratará de desenvolver uma teoria social periférica, voltada às questões nacionais, sem deixar de levar em conta cânones estrangeiros, mas os mitigando de acordo com as características locais. Por essa perspectiva, Guerreiro passará a estudar o pensamento político brasileiro, apresentando-se como herdeiro intelectual de um cânone que desde o século XIX estaria mais preocupado com a realidade nacional do que com fórmulas estrangeiras. Vimos que o auge dessa postura de Guerreiro fora sua atuação enquanto parlamentar na conturbada década de 1960. Enquanto o debate político acabava por se polarizar na Guerra Fria entre um projeto liberal e outro socialista, Guerreiro observou que essa polarização estava distante da resolução dos problemas nacionais do Brasil, sendo necessário pensar por uma chave de desenvolvimento nacionalista e autônoma.

Palavras-chave: Guerreiro Ramos. Redução sociológica. Pensamento político brasileiro. Nacionalismo.

\section{ABSTRACT}

Guerreiro Ramos is profiled among the most prominent Brazilian sociologists of the 2oth century, making a considerable contribution to the construction of an authentic and innovative sociology that would ultimately have the objective of dealing and solving concrete problems of political and social development in Brazil. We will analyze Guerreiro Ramo's theoretical development from the elaboration of the sociological reduction methodology in the 1950 s to his more eminently political works in the I960s. Based on the methodology provided by studies of Brazilian political thought, we will be able to see the formation of Guerreiro's social theory and his rejection of ready-made formulas developed in other countries to solve national problems. In this polemic, the sociological reduction will try to develop a peripheral social theory, focused on national issues, while taking into account foreign canons, but mitigating them according to local characteristics. From this perspective, Guerreiro will study Brazilian political thought, placing himself as the intellectual heir of a canon that since the Igth century has been more concerned with national reality than with foreign formulas. We point out the heights of this Guerreiro stance was his role as a parliamentarian in the troubled 1960s. While the Cold War political debate ended up polarizing into a liberal or socialist project, Guerreiro highlighted the fact that this polarization was far from solving national problems in Brazil, making it necessary to think about a key to nationalist and autonomous development.

Keywords: Guerreiro Ramos. Sociological reduction. Brazilian political thought. Nationalism. 


\section{INTRODUCÃO}

Alberto Guerreiro Ramos nasceu em I3 de setembro de I9I5 em Santo Amaro, na Bahia. Formou-se, em 1942, pela Faculdade Nacional de Filosofia do Rio de Janeiro em Ciências Sociais e, em 1943, em Direito. Foi assessor do presidente Getúlio Vargas em seu segundo governo (I95I-I954), atuando posteriormente como diretor do Departamento de Sociologia do então Instituto Superior de Estudos Brasileiros (Iseb).

Em 1960, Guerreiro Ramos ingressou na vida partidária: filiou-se ao Partido Trabalhista Brasileiro (PTB) e foi eleito para seu diretório nacional. Na eleição de outubro de 1962, candidatou-se a deputado federal pelo então estado da Guanabara, e obteve a segunda suplência. Com o afastamento de Leonel Brizola da Câmara dos Deputados, Guerreiro Ramos assumiu uma cadeira naquela casa, na qual permaneceu de agosto de 1963 até agosto de I964, quando teve seus direitos políticos cassados pelo ato institucional $\mathrm{n}^{\circ} \mathrm{I}$, após o golpe militar.

O presente trabalho busca analisar a atuação parlamentar de Guerreiro Ramos naquele curto período, em uma conturbada conjuntura política no Brasil. Buscamos analisar seus textos iniciais e a teoria social e pensamento sociológico brasileiro que o autor desenvolve para, posteriormente, analisar os textos que vieram a formar sua teoria política e pensamento político brasileiro. Isso se dá porque, apesar de tratar de distintos objetos durante sua obra, Guerreiro Ramos, desde o início de sua trajetória, está ciente da necessidade de se criar um pensamento de fato nacional, autêntico, atento às peculiaridades e às dificuldades apresentadas pela sociedade brasileira. Assim, rejeita fórmulas prontas ou "enlatadas", que partam do exterior para ser aplicadas ao Brasil sem um pensamento crítico.

Dessa maneira, nos parece que a atuação parlamentar de Guerreiro Ramos, para ser melhor compreendida, necessita de uma avaliação calcada no entendimento de sua obra desde suas formulações iniciais até seus textos mais maduros e na sua atuação, como ele próprio afirmara, ao realizar a crítica da sociologia de gabinete fora do gabinete. Assim, o presente trabalho se divide em três seções. Na primeira seção, buscamos entender o pensamento social de Guerreiro Ramos e suas peculiaridades e contribuições para a área. Na segunda seção, analisamos seus escritos políticos e vemos em que medida seus pressupostos teóricos e metodológicos permanecem ou são modificados nessa seara. Por fim, na terceira seção, vemos como, após longa formulação teórica, Guerreiro se posiciona na Câmara dos Deputados em meio a um movimento de extrema polarização na vida política brasileira, criticando o que chamaria de radicalismo de esquerda e de direita e buscando resolver, com lucidez e respeito às instituições, os problemas urgentes do Brasil, em uma perspectiva nacional-desenvolvimentista. 


\section{PENSAMENTO SOCIAL BRASILEIRO: A REJEIĈ̣̃O AO PENSAMENTO ENLATADO E A REDUÇ̃̃o SOCIOLÓGICA}

Já na Cartilha brasileira do aprendiz de sociólogo: prefácio para uma sociologia nacional (1954), Alberto Guerreiro Ramos levantou temas e debates que vieram a ser teorizados posteriormente em A redução sociológica (1955). Desde a Cartilha..., Guerreiro trata de temas centrais tanto para sua teoria social quanto para sua teoria política, que será vista adiante.

Respondendo a sociólogos que votaram contra suas recomendações enquanto presidente da Comissão de Estruturas Nacionais e Regionais no II Congresso LatinoAmericano de Sociologia, em 1953, Guerreiro inicia sua Cartilha... com uma polêmica que o acompanhará por muitos anos. Trata-se da polêmica sociologia enlatada versus sociologia dinâmica. Ele deixa claro, desde o início de seu trabalho, que "a melhor maneira de fazer ciência é a partir da vida, ou, ainda, a partir da necessidade de responder aos desafios da realidade" (GUERREIRO RAMOS, I954, p. I05).

Guerreiro percebe que um grande problema da sociologia brasileira, fruto de um país que fora colonizado e que ainda tinha como referência política, econômica e cultural o centro europeu, era justamente o uso das categorias sociológicas enlatadas, lá produzidas. Uma produção social autêntica deveria compreender, a particularidade da cultura local para a formulação de diagnósticos e resoluções de problemas políticos e sociais (FILGUEIRAS, 20I2, p. 348). Toda teoria social, que se pretendia universalista, partia da necessidade de resolução de problemas particulares. A assimilação do pensamento político formado no centro do capitalismo, quando assimilado na periferia - que era o caso do Brasil —, seria utilizado como valor universal, sem a devida atenção às particularidades da periferia, na divisão internacional de produção e circulação de conhecimento. O que Guerreiro buscava, então, em suas recomendações — que são o objeto de estudo da Cartilha... —, era

encorajar os esforços para a prática, nos países latino-americanos, de uma sociologia que refletisse os seus problemas; era estimular que se cortassem os cordões umbilicais que têm tornado essa disciplina subproduto abortício do pensamento sociológico europeu e norte-americano (GUERREIRO RAMOS, 1954, p. 19).

A partir disso, afirmou a existência de duas correntes de pensamento no Brasil naquele momento: uma "consular", enlatada, que admitia os preceitos desenvolvidos nos Estados Unidos e na Europa como válidos universalmente, de maneira acrítica; outra "autêntica", que, "embora aproveitando a experiência acumulada do trabalho sociológico universal, está procurando servir-se dele como instrumento de autoconhecimento e desenvolvimento das estruturas nacionais e regionais" (GUERREIRO RAMOS, 1954, p. I07).

A questão que nos é apresentada é o fato de Guerreiro não enxergar a sociologia como um fim em si mesmo. A tarefa do sociólogo não deve ser se tornar 


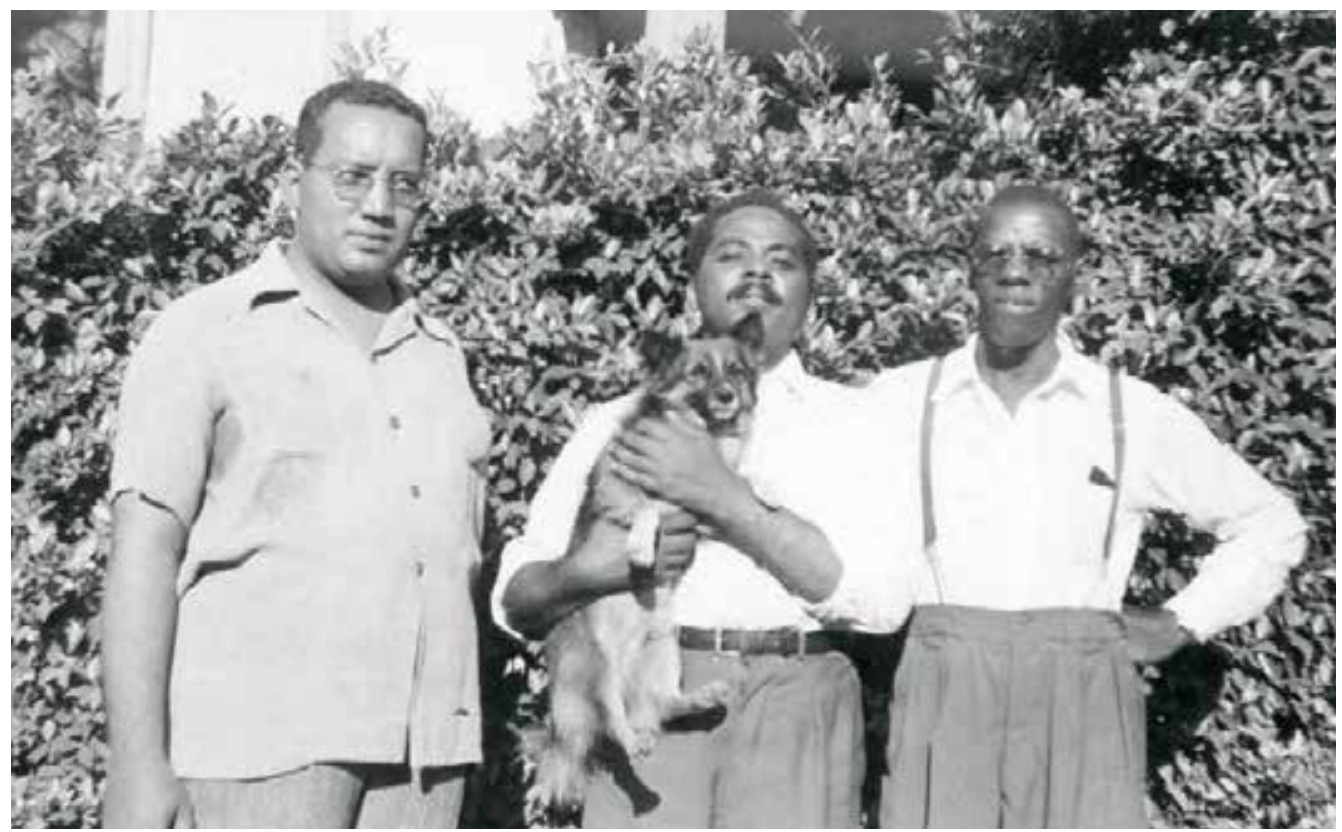

Alberto Guerreiro Ramos, Abdias do Nascimento e João Conceição na década de 1950

hábil em debater as diferentes teorias desenvolvidas no mundo cêntrico, sem uma preocupação com a realidade e o desenvolvimento nacional. É nesse sentido que afirma que a essência de toda sociologia autêntica é ser "um propósito salvador e de reconstrução social", e continua afirmando que, "na medida em que o sociólogo exercita vitalmente a sua disciplina, é forçosamente levado a entrelaçar o seu pensamento com a sua circunstância nacional ou regional" (GUERREIRO RAMOS, I954, p. IO7).

Como argumenta Lynch, "tratava-se de pensar a teoria social geral como capaz de reconhecer o caráter histórico e culturalmente condicionado de todos os fenômenos sociais e, assim, apreender o caráter dinâmico e situado da realidade" (LYNCH, 20I5, p. 30). Para Guerreiro, portanto, a emergência de uma sociologia nacional teria um grande caráter prático. Para ele, segundo Lynch, "os cientistas da região deveriam contribuir para a superação das mazelas do caráter periférico e, portanto, heterônomo, do subcontinente, envolvendo-se no esforço de autodeterminação de suas sociedades" (LYNCH, 20I5, p. 32). Ele parte então para a construção de um novo método - a redução sociológica - "que permitisse ao cientista social periférico adaptar as teorias estrangeiras [...] às necessidades da própria etapa de desenvolvimento experimentada pela coletividade em que vivia" (LYNCH, 2015, p. 33).

Como dito, Guerreiro buscava para a sociologia um sentido prático, fazendo com que o avanço científico experimentado pelas ciências sociais fosse capaz de resolver o atraso brasileiro (FILGUEIRAS, 2012, p. 349). O autor "procurou defender uma sociologia engajada, com a preocupação constante de influenciar [a] e participar da vida política e nacional" (FILGUEIRAS, 20I2, p. 349). Assim, a redução sociológica será uma atitude metódica crítico-assimilativa e inovadora, não negando pressupostos 
teóricos estrangeiros, mas compreendendo que estes foram gestados em conjunturas distintas e precisam ter suas perspectivas cotejadas com as particularidades do desenvolvimento nacional local, no caso, brasileiro. Assim, para Ramos, a ciência social seria capaz de abandonar uma perspectiva puramente acadêmica e se debruçar sobre a realidade local, com a intenção de a transformar. É a partir dessa nova premissa teórica que Guerreiro desenvolve sua teoria política, como veremos na seção a seguir.

\section{TEORIA POLÍTICA DE GUERREIRO RAMOS}

Pode-se ver que, desde o começo da trajetória de Guerreiro Ramos, a formação de um pensamento político alia-se à prática política. Antes de ser deputado federal, além de ter assessorado Getúlio Vargas durante seu segundo governo (195I-1954), foi diretor do Departamento de Sociologia do Iseb, instituição criada em julho de 1955 como órgão do Ministério de Educação e Cultura, durante o governo João Café Filho (1954-1955).

O Iseb destinava-se ao estudo, ao ensino e à divulgação das ciências sociais, cujos dados e categorias seriam aplicados à análise e à compreensão crítica da realidade brasileira e à elaboração de instrumental teórico que permitisse o incentivo e a promoção do desenvolvimento nacional. No Iseb, Guerreiro Ramos realizou uma crítica do pensamento social brasileiro com vistas a construir uma sociologia nacional. Deu-se conta de mudanças correntes na sociedade brasileira que necessitavam de dedicada análise. O Brasil, à época, era um país em plena transformação. Deixava de ser, como o autor mostra empiricamente, uma sociedade rural, e transformava-se em uma sociedade urbana e de massas.

Segundo Guerreiro, era necessária uma compreensão política acerca das transformações socais pelas quais o país passava. Desse modo, parte da sociologia para a análise dos grupos políticos em voga no país, percebendo a ideologia que carregavam. Intuitivamente, salta da sociologia para a ciência política. Assim como, anteriormente, realizou uma história crítica do pensamento social brasileiro, então, com a mesma metodologia, realiza uma história crítica do pensamento político brasileiro.

\section{I. História política, grupos políticos e ideologia política}

No prefácio de O problema nacional do Brasil (1960), Guerreiro Ramos parte do pressuposto de que "somente a partir de certo nível de desenvolvimento, o trabalho científico adquire relevante eficácia social" (GUERREIRO RAMOS, 1960, p. I8). Ademais, parte da suposição de que é nos países "em que os fatores intelectuais se tornaram de aplicação rígida, isto é, se tornaram verdadeiros fatores de produção, que se está fazendo a melhor teoria sociológica" (GUERREIRO RAMOS, 1960, p. I8). Claro está, portanto, que naquele momento, para Guerreiro, o caráter prático da ciência social é essencial, dando suporte teórico efetivo ao desenvolvimento nacional. Retoma a perspectiva de Alberto Torres, autor de $O$ problema nacional brasileiro (1914), afirmando 
que realiza, como esse autor, uma "tentativa de utilizar a ciência social como instrumento de organização da sociedade brasileira" (GUERREIRO RAMOS, I960, p. I8).

Em "A dinâmica da sociedade política no Brasil", presente no livro Introdução crítica à sociologia brasileira, Guerreiro analisa o desenvolvimento da política brasileira, dando ênfase à identificação dos grupos sociais então atuantes e à explicação da forma pela qual eles expressavam coletivamente determinadas ideologias ante o momento transitório na vida política e social que o Brasil atravessava. Ao denunciar o "descritivismo casuístico", que leva grande parte dos sociólogos brasileiros a adotar, de maneira acrítica, as teorias produzidas no centro, ineficazes à resolução dos problemas nacionais, buscava efetivar uma análise sociológica orientada, isto é, "uma teoria da sociedade brasileira que sirva de suporte à estruturação efetiva das tendências de autodeterminação vigentes hoje em nosso país" (GUERREIRO RAMOS, I995b, p. 60).

Naquele momento, distingue dois tipos de teorização da realidade social: a ideológica e a sociológica (ou científica). A ideológica seria, necessariamente, "sectária nisto que visa a justificar os interesses particulares de um grupo ou uma classe". A sociológica consistiria, por outro lado, em examinar a "influência dos fatores irracionais no pensamento", se aplicando "na compreensão global da sociedade”. É uma "atitude crítica e autocrítica, radical, interessada em formular uma concepção configurada da realidade social". Teorização científica essa que "não escapa do condicionamento histórico social” (GUERREIRO RAMOS, I995b, p. 65).

No momento em que Guerreiro Ramos escreve, o Iseb trata a luta ideológica como central para o desenvolvimento nacional. As mudanças na sociedade brasileira - como aponta Guerreiro - estavam ocorrendo de maneira extremamente rápida, precisando ser compreendidas e, mais que isso, influenciadas e direcionadas. Nesse sentido, a tarefa do cientista social deveria ser ampla, pautada pela realidade que o país atravessava, buscando promover seu desenvolvimento para além de interesses de grupos político-partidários.

De acordo com a análise feita por Guerreiro naquele estágio do desenvolvimento capitalista em que o país se encontrava, a disputa entre os diferente grupos e classes sociais era complexa. Tentando compreender a situação brasileira, ele forma três tipos ideais para analisar a conjuntura política, quais sejam: grupos de ascensão, de domínio e de decadência (GUERREIRO RAMOS, I995b).

Classes e grupos ascendentes, grupo no qual Guerreiro se insere, por sua própria origem social, são levados a discernir, na estrutura social, as virtualidades, as possibilidades de desenvolvimento, os aspectos potenciais e, assim, assentam a sua mira no vir a ser, no futuro. O panorama geral do desenvolvimento do pensamento político brasileiro não deixa de ser, então, atrelado ao desenvolvimento econômico, político e social.

Por outro lado, a burguesia nacional se encontrava em uma posição de ascensão juntamente com a nova classe proletária, e logo poderia se colocar em uma posição de dominância. Guerreiro explica isso pelo fato de serem tais posições fases 


\section{A realidade brasileira no início da década de 1960 passava por \\ um novo momento, e Guerreiro \\ via como necessária a criação \\ de uma teoria política autêntica, \\ que acompanhasse aquelas \\ transformações e desse subsídios a mudanças políticas, econômicas e sociais que o país deveria atravessar}

pelas quais as classes sociais passam (GUERREIRO RAMOS, 1995b). Continua ao afirmar que, ao atingirem a posição de domínio, as classes ascendentes são acometidas das mesmas distorções volitivas e de captação do real características das classes que as precedem (GUERREIRO RAMOS, I995b). Tornam-se, assim, segundo Guerreiro, antidialéticas, proclamando a necessidade da ordem.

Sobre as transformações econômicas e estruturais pelas quais a sociedade brasileira passava, Guerreiro demonstra que, até 1930, "nenhum movimento político ultrapassava a perspectiva da classe média”. Naquele período, entretanto, começa a delinear-se como força política o proletariado brasileiro, que constitui a base eleitoral de um dos maiores partidos do Brasil durante a república instalada em 1946: o Partido Trabalhista Brasileiro (PTB).

Nesse sentido, afirma:

A revolução de 1930 promoveu, entretanto, mudanças de sinal positivo na vida político-partidária do país, pelo menos em decorrência dos seguintes fatos: a) abriu lugar nos quadros dirigentes para consideráveis contingentes da classe média; b) iniciou a institucionalização das forças econômicas, através da sindicalização; c) iniciou o processo de liquidação, no Governo Federal, da hegemonia de uns poucos estados em detrimento dos restantes; d) firmou o princípio da intervenção do Estado na economia, embora sob a forma de um "dirigismo" desconexo e às vezes caótico (GUERREIRO RAMOS, 1995, p. 97).

A crise da organização político-partidária se deu, entretanto, no momento em que o autor escrevia, pelo fato de que "ela não ultrapassou aquelas direções formadas entre 1930 e $1937 \mathrm{e}$, portanto, o seu desajustamento aos fatores objetivos que configuram a realidade brasileira" (GUERREIRO RAMOS, I995b, p. 97). Naquele momento, 
é forte o interesse de Guerreiro Ramos pela vida política brasileira, o que fará com que ingresse na vida partidária do país em I959, quando se filia ao PTB, cujo diretório nacional chegou a compor. Inicia-se, então, o esforço de teorização de Guerreiro, feito à luz de sua funcionalidade na prática.

\subsection{A revisão crítica do pensamento político brasileiro}

A realidade brasileira no início da década de 1960 passava por um novo momento, e Guerreiro via como necessária a criação de uma teoria política autêntica, que acompanhasse aquelas transformações e desse subsídios a mudanças políticas, econômicas e sociais que o país deveria atravessar. Não havia espaço para teorias tautológicas deslocadas das realidades, peculiaridades, e transformações que o país vivia. Estudando a história política do Brasil, Guerreiro encontra na década de $1930 \mathrm{um}$ momento de efervescência da política nacional, e enxerga, naquela polarização, algo que justifica a polarização que vivia e estudaria: a do final da década de 1950 e início da década de 1960.

A partir de seus esforços de teorização da realidade política brasileira, Guerreiro analisa as ideologias da década de 1930 que ainda eram presentes à época em que escreve, porém, em constante mudança. Esse esforço se consolidou em seu texto "Três momentos ideológicos do Brasil", que veio a fazer parte de seu livro A crise do poder no Brasil (196I). Guerreiro diz que "no domínio da vida intelectual, há famílias", que seriam "grupos cujos integrantes são marcados sutil ou ostensivamente por um ar de família" (GUERREIRO RAMOS, I96I, p. I4I). Trata no livro de duas dessas famílias, a saber: a "jeunesse dorée" e os "sociólogos anônimos", escritores sem qualificação acadêmica que, no entanto, contribuíram para o esclarecimento da Revolução de 1930 e suas consequências. Nessa morfologia, diz, constituirão também uma família, no Brasil, homens que professam o catolicismo de uma maneira particular. Seriam estes "cidadãos que falam em seu nome [da Igreja Católica], sem todavia terem compreendido a verdadeira significação de seu magistério". Seria esse o movimento do integrismo, que assim Ramos define:

O integrismo é, entre outras coisas, um excessivo compromisso com as formas temporais da Igreja e, assim, vitimiza aqueles que não distinguiram no catolicismo o núcleo de suas crenças básicas de suas expressões adjetivas. Cometem-no, por exemplo, os que pensam que o catolicismo está indissoluvelmente ligado a uma forma particular de organização econômica da sociedade [...]. O integrista focaliza esse assunto à luz de uma espécie de dialética do Bem e do Mal, de uma espécie de maniqueísmo que divide a humanidade em dois campos, em duas espécies irredutíveis (GUERREIRO RAMOS, I96I, p. I42).

O integrismo tem se identificado no Brasil com o que Guerreiro chama de "ideologia da ordem", cujos defensores compõem o primeiro grupo a ser tratado pelo 
autor. Figura central desse movimento seria o sergipano Jackson de Figueiredo, que, para Guerreiro, era, "em política, um conservador. Toda a sua ação era subordinada ao princípio da ordem, não justificando nenhuma forma de conduta revolucionária." (GUERREIRO RAMOS, 196I, p. I44)

Essa corrente de pensamento política era analisada sob um prisma moral, que se distanciava das transformações econômicas e sociais da sociedade. A consequência prática dessa concepção política foi o reformismo, e nunca uma "alteração das relações de classe, a transformação mesma da estrutura social” (GUERREIRO RAMOS, I96I, p. I46). A ideologia da ordem, desde a década de I920, já defendia pontos que seriam essenciais ao integralismo - a expressão brasileira do fascismo, a saber, o corporativismo e a aversão à liberal-democracia. Claro era, portanto, o caráter reacionário dessa doutrina.

Então, passa a analisar a outra família de pensamento, a "jeunesse dorée". Diz que esses autores possuem um pensamento descompromissado com as condições materiais e concretas da sociedade. Produzem intelectualmente em caráter fictício. A "jeunesse", "estratos de intelectuais bem nascidos, para os quais as dificuldades materiais propriamente não existem" (GUERREIRO RAMOS, I96I, p. I52), vê as mudanças por que passa a sociedade e as toma como perda de privilégios, acabando por se afirmar como pensadores reacionários.

Guerreiro mostra que essa literatura carece de conteúdo científico, e só teve condições de se propagar no Brasil pelas próprias condições materiais do país. A política seria aqui tratada de maneira genérica e abstrata, sem se ater às peculiaridades econômicas e sociais que vive o país no momento em que é produzida. Guerreiro diz, em contrapartida, que, quanto mais puro o pensamento, mais impotente ele será. Seriam representantes desse pensamento Afonso Arinos e Otávio Faria, entre outros.

Essa ideologia era expressiva da sociedade latifundiária, que já havia sido dominante no país, estava em decadência e se posicionou de forma reacionária em relação às transformações que o país atravessava. Diz Guerreiro que, para esses autores:

A estrutura econômica e social, na qual a classe dirigente era constituída de grandes proprietários de terras, devia conservar-se imutável, sendo imorais e satânicas as tendências que laboravam por sua transformação qualitativa (GUERREIRO RAMOS, 196I, p. 153).

Por fim, Guerreiro trata do "inconsciente sociológico", fruto do pensamento orgânico que se difundiu no Brasil após 1930. Guerreiro tenta recuperar autores de uma sociologia prática e engajada, autores do inconsciente sociológico, quais sejam, José Maria dos Santos, Martins de Almeida, Caio Prado Júnior e Azevedo Amaral. Há aqui, segundo Guerreiro, um pensamento com caráter científico, progressista, e não conservador. O político não é explicado por si próprio, mas por uma base socioeconômica. $\mathrm{O}$ estudo dessas obras se fez imperativo para formar uma teoria da realidade brasileira. 
Os autores aqui mencionados, segundo Ramos, "acertaram muito porque seguiram o caminho empírico-dedutivo na elaboração de suas ideias" (GUERREIRO RAMOS, I96I, p. I68). Naturalmente, cometeram erros, como incorrer no "psicologismo e carecerem de uma teoria social orgânica" (GUERREIRO RAMOS, I96I, p. I69). A despeito disso, foram os autores que até então melhor tinham compreendido o Brasil. Eram os autores do "inconsciente sociológico", justamente por não terem as categorias técnicas para descrever o desenvolvimento objetivo e necessário da sociedade brasileira. Ao estudar esses autores, Guerreiro se dá conta da importância do Estado Novo na formação da sociedade brasileira, para a qual se tornou necessário um sentido mais intervencionista do Estado, com o intuito de eliminar as barreiras interestaduais que dificultavam o pleno funcionamento de um mercado interno (GUERREIRO RAMOS, I96I, p. I72).

Após uma revisão crítica do pensamento político brasileiro até então produzido, rejeitando o pensamento reacionário e moralista, que não atentava aos fatores reais de mudança, e se apoiando em autores que, mesmo sem bases teóricas suficientes, conseguiram entender as transformações que o país atravessava, Guerreiro se apresenta como herdeiro dessa linhagem. Estava então imbuído de conhecimento científico suficiente para esboçar uma teoria política pós-colonial que pudesse dar sustentação ao desenvolvimento do Brasil, com a própria transformação de suas relações sociais. É disso que trataremos a seguir.

\subsection{Consolidação e esboço de uma teoria política pós-colonial}

Aqui estão apresentados os resultados da pesquisa de Guerreiro Ramos para analisar e referenciar o momento de transição que o país então atravessava. Teoricamente, o nacionalismo encaminharia à industrialização e ao crescimento das forças produtivas. A partir disso, Guerreiro aproxima-se do trabalhismo, buscando construir um partido de esquerda, de massas, e que não fosse comunista - ou seja, não seguidor de uma doutrina que para o autor era uma cultura alienígena ao Brasil. Busca, enfim, construir um argumento nacionalista e de esquerda.

Falar de esboço para uma teoria pós-colonial em Guerreiro Ramos nos remete ao que afirma Filgueiras:

De acordo com essa premissa que caracteriza o pensamento pós-colonial, a condição de colônia não se resume a um arranjo político e econômico de opressão e exploração, mas também à construção de uma cultura subalterna, em que os valores e as percepções de mundo se alinham aos valores e percepções constituídas pela cultura ocidental. O colonialismo não é apenas um arranjo de exploração econômica. É, também, uma condição de subalternidade da cultura nativa, que tem consequências na construção de identidades. O sujeito colonizado é aquele que, em detrimento de sua cultura nativa, se submete aos valores e percepções constituídas pela cultura moderna (FILGUEIRAS, 20I2, p. 347). 
É possível pensar em Guerreiro Ramos por essa perspectiva, visto que sua leitura do pensamento político brasileiro terá como perspectiva central a valorização da produção cultural e intelectual local, necessária para a "constituição de um significado para o nacionalismo brasileiro no contexto do desenvolvimento nacional" (FILGUEIRAS, 20I2, p. 348). João Maia mostra que há uma virada periférica na obra de Guerreiro após uma viagem que ele fez em 1956 a Paris, cidade que teria se tornado "um verdadeiro centro da diáspora de intelectuais africanos e caribenhos das colônias, que logravam constituir laços de solidariedade transcontinental justamente no coração da metrópole colonizadora (MAIA, 20I5, p. 5I). Pensando na constante relação entre pensamento social e prática política, Guerreiro levanta a hipótese de que países anteriormente vistos como subdesenvolvidos, como Rússia, Índia, China e Japão, "teriam logrado transformar o conhecimento sociológico em instrumento de construção nacional" (MAIA, 20I2, p. 52). É nessa perspectiva que o autor fará uma leitura historicamente fundamentada do pensamento político brasileiro.

Em "Caracteres da intelligentsia", artigo no livro A crise do poder no Brasil (196I), Guerreiro defende, sociologicamente, um pensar independente. $\mathrm{O}$ intelligentsista procura obter a suspensão dos estereótipos a respeito dos temas e, assim, examiná-los de maneira crítica. Esse tipo de intelectual, segundo Guerreiro, começa a surgir no Brasil apenas no momento em que o autor escreve. Ele afirma:

Esses intelectuais fazem realmente política, exibem na sociedade brasileira um estilo de vida intelectual que contraria as expectativas até agora dominantes, entre nós, a respeito do que devem ser as pessoas cultas. Por motivos que não podemos examinar aqui, formou-se no Brasil uma concepção segundo a qual a vida da inteligência é incompatível com a política. Os adeptos dessa concepção tomam-se de susto ante a existência de intelectuais que se afirmaram também políticos. Se, porém, tiverem boa-fé, verificarão que esse espanto é injustificado. Ao contrário, num país como o Brasil, o intelectual que viva profundamente a ética da inteligência reconhecerá que o seu magistério terá de ser deliberadamente, intencionalmente político. Não é inteligente ser de outra maneira. Há na sociedade brasileira, atualmente, um oco a preencher, que decorre da perda de exemplaridade das ideias, por meio das quais justificava sua dominação uma classe há duas décadas em processo de aposentadoria histórica. Está diante de nós a tarefa de organizar um Estado nacional, ou seja, de configurar politicamente o povo brasileiro. Para o intelectual, assumir essa tarefa não corresponde a ser adminículo de uma 
classe particular. Nas condições atuais da sociedade brasileira, está aberta ao intelectual, pela primeira vez entre nós, a oportunidade de valer por si, na proporção do teor concreto das ideias que exprime. Tais condições necessariamente politizam o trabalho intelectual orientado por um propósito substitutivo (GUERREIRO RAMOS, I96I, p. I89-190).

Fica evidente aqui, em Guerreiro Ramos, seu pensamento nacionalista. Assim como baseou na redução sociológica a sua teoria social, a sua teoria política deve ser feita em bases nacionais, atento às suas particularidades. $\mathrm{O}$ nacionalismo brasileiro não é o nacionalismo europeu. É uma posição defensiva no processo de criação da nação. O nacionalismo é dado como uma consequência, no plano cultural, da emergência da nação. É um pensamento de caráter autônomo, que desembocará em uma ideologia nacional-desenvolvimentista que terá sua representação política no PTB. O nacionalismo é tido como motor ideológico que resultará no desenvolvimento. Guerreiro dirá então que o nacionalismo não tem apenas fundamento psicológico. Tem também fundamento econômico (GUERREIRO RAMOS, I96I).

Assim, afirma em "Nacionalismo e xenofobia", artigo que compõe o livro Introdução crítica à sociologia brasileira (I957), que "nada tem a ver com xenofobia a posição nacionalista que vêm assumindo crescentemente os intelectuais mais representativos das tendências atuais do Brasil" (GUERREIRO RAMOS, 1995b, p. 55). Ao contrário, o nacionalismo na fase em que a sociedade brasileira se encontrava seria algo ontológico, verdadeiro processo e princípio permeador do povo, expressão da emergência nacional.

Naquele momento, fica evidente que Guerreiro Ramos passa a se ver como um intelectual em ação. E é então que se torna ativa sua carreira na política militante. Parte de um pressuposto de que era possível e necessária a conciliação entre militância e ciência social. Acreditava, como visto, viver em um momento crucial da formação do Estado e da sociedade brasileira. O intelectual deve se preocupar com a produção de ideias e se condicionar socialmente, buscando o desenvolvimento nacional. Deve se colocar como um instrumento transformador da realidade. O intelectual público deve seguir o padrão da exemplaridade.

Em "Condições sociais do poder nacional", que constitui O problema nacional do Brasil (1960), faz uma apresentação sistemática da ideologia. Assim se torna capaz de demonstrar o que seria a ideologia progressista do momento. Amparado na teoria da sociedade brasileira, esse foi o primeiro texto de conclusão desse percurso. $\mathrm{O}$ problema nacional teve então sua compreensão no aspecto sociológico, e não jurídico-formal, por meio de uma abordagem dinâmica dessa teoria. Guerreiro fez aqui uma articulação entre os seus pensamentos social e político. Busca uma explicação sociológica de nossa realidade, olhando o passado político brasileiro por uma chave de análise negativa. Em decorrência disso, nos países periféricos, como o Brasil, o Estado aparece, historicamente, antes da sociedade civil. 
O Estado cria a sociedade, mas essa situação está prestes a se inverter em face de uma nova conjuntura, em que o Brasil passa pelo fenômeno da emergência do povo como nova categoria social, e se torna uma sociedade de classes. Chega, portanto, o momento de fazer uma ideologia para as massas. Como afirma Guerreiro, são grandes as transformações no período:

Formou-se uma população obreira e uma burguesia empreendedora, cujos interesses dependem do consumo interno, e que, compondo a matriz de um verdadeiro povo, constituem hoje a maior força política do Brasil (GUERREIRO RAMOS, 1960, p. I8).

As classes sociais no Brasil, pela primeira vez na história, passam a ter expressão ideológica. Em um contexto de crise, se fazia necessário que a burguesia industrial assumisse o poder no Brasil, em uma encruzilhada em que o país se encontrava entre autonomia e dependência. $\mathrm{O}$ problema do desenvolvimento econômico se caracterizava como questão política.

Se as condições materiais estavam presentes para uma revolução nacional brasileira, pautada pelo desenvolvimento econômico e social, os grupos políticos não conseguiam lidar com essa nova realidade, com a emergência do povo, e o Brasil encontrava-se em um grande impasse. Naquele momento, o nacionalismo era central, sendo mais do que o amor à terra e a lealdade aos símbolos que a representam, mas um projeto de elevar uma comunidade à apropriação total de si mesma (GUERREIRO RAMOS, 1960).

Alimentado pela conjuntura internacional, com processos de luta pela identidade nacional e pela descolonização na África e na Ásia, Guerreiro Ramos defenderá o alinhamento do Brasil aos países subdesenvolvidos — o dito Terceiro Mundo. Buscando o exemplo africano e asiático, ele escreve:

O comportamento internacional da periferia latino-americana, de que faz parte o Brasil, está longe de poder equiparar-se ao da periferia afro-asiática. Nas condições atuais da América Latina, econômicas, políticas, sociais e geográficas, ainda são escassas as reais possibilidades de emergência de uma conduta externa totalmente liberta de pressões heterônomas. $\mathrm{O}$ fundamento da terceira posição internacional não é um mero estado de espírito ou opção abstrata. A terceira posição sustenta-se em possiblidades reais contidas no processo de cada nação, e torna-se utópico quando essas possibilidades não existem. [...] Mas, entre a terceira posição utópica e a sistemática há, para alguns países latino-americanos, especialmente o Brasil, a possibilidade real de uma terceira posição empírica ou tópica (GUERREIRO RAMOS, 1960, p. 38).

Dessa maneira, como lutou contra a transplantação de teorias sociais estrangeiras para o Brasil, agora fica clara sua luta por um desenvolvimento autônomo da política nacional. Esse fato levou Guerreiro, como será visto adiante, a polemizar 


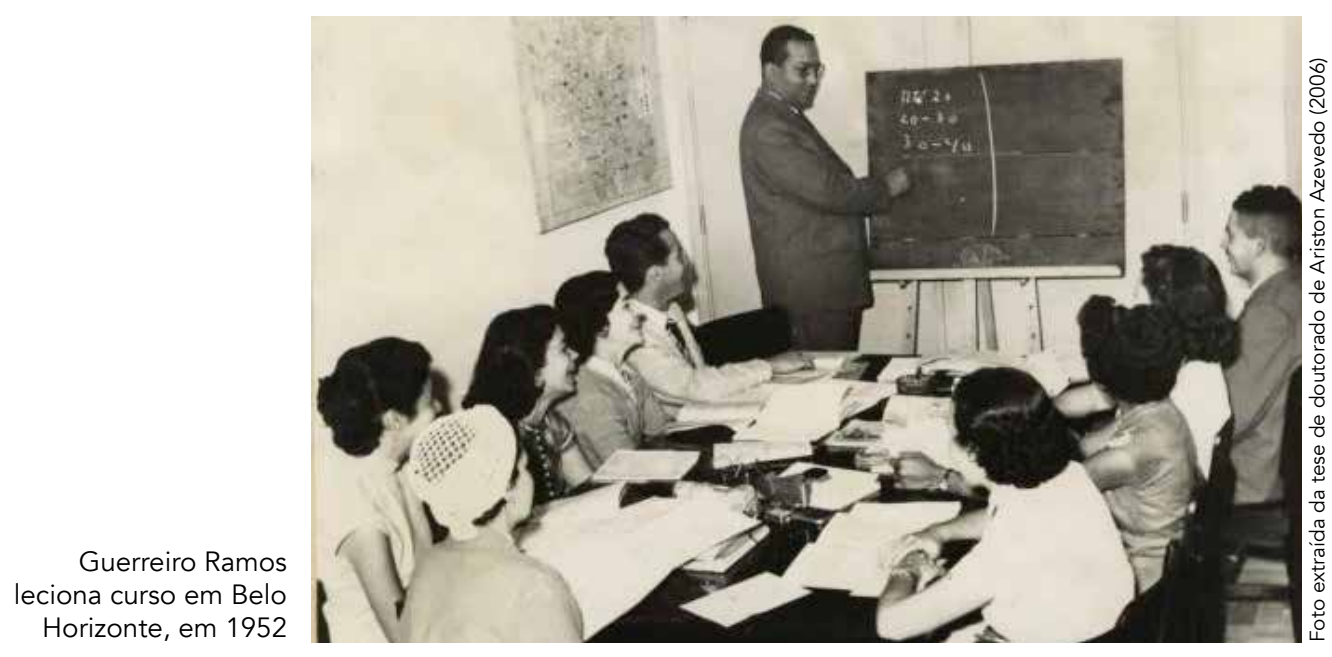

tanto, por um lado, com a direita, que se aproxima dos Estados Unidos da América (EUA), quanto, por outro lado, com a esquerda, que se aproxima da União das Repúblicas Socialistas Soviéticas (URSS), como se fossem modelos universais a ser seguidos, resumindo a luta política à adesão a um desses dois projetos. Em contrapartida, Guerreiro afirma que o desenvolvimento nacional não passa por esses dilemas, mas por dilemas inerentes ao Brasil. Mais uma vez, ele rejeita o exemplarismo e busca construir um pensamento autêntico no país.

Em "Ideologia e segurança nacional", outro artigo de $O$ problema nacional do Brasil, Guerreiro conclui seu empreendimento de estabelecer o conceito de ideologia e sua existência e funcionamento no Brasil. A segurança nacional, então, passa a ter um espaço central no debate público, principalmente com a publicação de $A$ geopolítica no Brasil, de Golbery do Couto e Silva, em I958. Naquele texto, ele realiza, inicialmente, um breve histórico do conceito de ideologia, demonstrando que a linha conceitual que busca desenvolver se distancia da marxista - como falsa consciência, notadamente na obra A ideologia alemã(I848). Como afirma Guerreiro:

De início, os marxistas usaram o termo unilateralmente. Serviam-se dele como arma de combate contra os seus adversários políticos. Ao qualificarem de ideológicas as teorias e ideias alheias, visavam a denunciá-las como disfarces e justificação de interesses. Isso não impediu, no entanto, que viessem a considerar sua própria doutrina como ideologia; no caso, a ideologia do proletariado (GUERREIRO RAMOS, I960, p. 45).

Para Guerreiro, entretanto, “aquilo que nos estudos de Marx e Engels era incidental passou a ser, no âmbito da sociologia do conhecimento, a matéria de uma teoria sistemática do pensar e do agir humanos" (GUERREIRO RAMOS, I96I, p. 48). O que passa a importar para Guerreiro é a maneira pela qual a ideologia se instrumentaliza na sociedade. Mostra, assim, em referência à política de segurança nacional, que não existe ideologia neutra em si mesma. 


\title{
A ideologia deve criar a consciência política que mobilizará o povo, que deve ser ator do desenvolvimento democrático da nação. O exercício do poder pelo povo deve partir de uma ideologia e de uma institucionalidade partidária, mobilizando a pressão popular por mudanças
}

Há aqui uma clara prevalência do político em relação às demais instâncias sociais. Para uma política de segurança nacional autônoma e independente, seria necessário um país autônomo e independente, apto a se desenvolver economicamente. O desenvolvimento político, entretanto, não se mostraria possível sem um desenvolvimento das forças produtivas do país. Nesse sentido, diz:

\begin{abstract}
Um país economicamente dependente terá uma existência tributária dependente, e sua política de segurança nacional refletirá necessariamente essa condição, isto é, terá de enquadrar-se, de modo complementar, na estratégia geral do centro de poder em cuja órbita de gravitação se encontra. Outra será a política de segurança nacional de países em processo de descolonização de sua economia ou já plenamente desenvolvidos. Nesse caso, o seu conteúdo fundamental é, propriamente, a autodeterminação (GUERREIRO RAMOS, I960, p. 67).
\end{abstract}

O problema da segurança nacional no Brasil se dava pelo fato de ser esse um país em transição desde 1930. Essa transição ocorre, segundo Guerreiro, em todos os níveis da vida nacional. A ideologia, portanto, deveria ser percebida e instrumentalizada teoricamente, em uma verdadeira ideologia da funcionalidade. O desenvolvimento nacional é dinâmico, sendo importante e necessário o processo de tomada de consciência. A segurança nacional seria então, para Guerreiro, o combate a entraves internos e externos ao desenvolvimento. Colocando-se à esquerda no espectro político, sua questão central é a função que a ideologia exerce nesse momento.

Por fim, realiza a crítica a dois pensamentos "alienados" que polarizavam a opinião pública e intelectual à época. De um lado, os comunistas poderiam ser vistos 
como radicais, mas eram alienados em relação à realidade nacional, e agentes do que Guerreiro via como antinacionalismo e ameaça à segurança nacional. De outro lado, criticou o liberalismo da União Democrática Nacional (UDN), acusando-a de ter um posicionamento periférico e entreguista. O Brasil não deveria se curvar a uma grande potência, quer sejam os EUA, quer seja a URSS. Deveria, ao contrário, tirar o melhor partido das oportunidades que lhe oferecia a conjuntura mundial, em um sentido histórico favorável ao seu desenvolvimento (GUERREIRO RAMOS, I960).

Após desenvolver seu pensamento a respeito da ideologia, em Estrutura atual e perspectiva da sociedade brasileira (1957) instrumentaliza essa ideologia para o desenvolvimento nacional. O desenvolvimento econômico é visto como um problema político. A programação econômica deve ser feita em bases nacionais, inexistindo um desenvolvimento político autônomo sem uma ideologia autônoma. O planejamento econômico é submetido a uma ideologia nacional-desenvolvimentista.

A ideologia deve criar a consciência política que mobilizará o povo, que deve ser ator do desenvolvimento democrático da nação. O exercício do poder pelo povo deve partir de uma ideologia e de uma institucionalidade partidária, mobilizando a pressão popular por mudanças. Naquele momento, o ator histórico da mudança seria justamente o PTB, ao qual Ramos se filiou e pelo qual ocupou uma cadeira na Câmara dos Deputados até ser cassado pelo ato institucional $\mathrm{n}^{\circ} \mathrm{I}$. Na próxima seção deste trabalho, a seguir, trataremos dos escritos de Guerreiro Ramos no momento em que esteve mais envolvido na militância político-partidária e, posteriormente, propriamente da sua atuação parlamentar. Com isso, busca-se verificar até que ponto sua teoria foi levada ao Congresso Nacional, e como ela influenciou o deputado Guerreiro Ramos.

\section{MILITÂNCIA POLÍTICA E ATUAC̣̃̃o PARLAMENTAR}

Em seu livro A crise do poder no Brasil (196I), Guerreiro se depara com a grave crise de representatividade político-partidária que o país atravessa devido à sua nova realidade e recentes transformações. Em luta contra as classes decadentes, o Congresso poderia ser o local em que o povo - categoria emergente - resistiria aos poderes oligárquicos representados pelo Executivo. Há aqui uma conclusão diferente da de autores que o inspiraram, como Alberto Torres e Oliveira Vianna, sobre a relação entre Poder Executivo e Poder Legislativo.

A grande questão se dava pelo fato de que, quando esses autores escreveram, as condições materiais do país não permitiam outra análise, de acordo com Guerreiro. O Brasil não tinha povo, e, assim, a democratização viria do próprio Estado contra o mando oligárquico local. Quando escreve, entretanto, a situação é outra - e não foi acompanhada pela estrutura institucional.

O povo, que inexistia na Primeira República, emerge então como nova categoria sociológica. Assim, há uma renovação teórica da própria corrente de pensamento 
da qual Guerreiro se julga representante. Se, anteriormente, a crise de representatividade se deu pela ausência de povo, agora se dava justamente pela presença do povo e pela ausência de mecanismos institucionais necessários para sua manifestação política. Os partidos políticos precisavam se democratizar internamente, se transformando em partidos de massa. A política deixa de ser vista unicamente como questão acadêmica e se torna questão de práxis.

Apesar de Guerreiro se posicionar à esquerda no espectro político, enxergava que a esquerda brasileira passava por um grande problema, que deveria ser superado. Esse problema seria a influência do Partido Comunista do Brasil (PCB) e do pensamento marxista-leninista na esquerda brasileira, inclusive em quadros do próprio PTB. Para ele, marxismo-leninismo não seria mais que a transplantação de um fenômeno russo, que ocorreu de maneira exitosa à sua época, mas que não atentava às características do Brasil. Esse posicionamento fica claro em seu livro Mito e verdade da revolução brasileira (1963). Ele chega a afirmar em plenário que "o marxismo-leninismo não é um pensamento, não é uma teoria; o marxismo-leninismo é uma organização de combate e de choque que manipula uma técnica de agitação e propaganda, com o objetivo de assaltar o poder; é uma organização destituída ou esvaziada de conteúdo ético" (GUERREIRO RAMOS, I963, p. 48).

Mostra grande preocupação com o sentido que tomarão os rumos do nacionalismo brasileiro, tachando muitas vezes a atuação dos pecebistas de "transplantativa", por adotar acriticamente as diretrizes da III Internacional, de um lado, e julgando-os mais interessados no crescimento do seu grupo do que no desenvolvimento nacional, de outro. A revolução brasileira - iniciada em 1930 - teria suas próprias peculiaridades, às quais o pesquisador e o militante político deveria atentar. Como afirma Motta:

A crítica de Guerreiro ao PCB começou a se desenvolver em seu livro anterior, A crise do poder no Brasil, de I96I, no qual considerava o referido partido uma organização alienada das camadas sociais que, presumivelmente, deveria representar, e também subordinado diretamente à URSS. A preocupação de Guerreiro Ramos com relação ao PCB devia-se, também, por este possuir, na época, a hegemonia intelectual e política no campo da esquerda (MOTTA, 20I0, p. 93).

Após longo amadurecimento teórico e estudo das ideias políticas brasileiras desde o século XIX até a sua contemporaneidade, com a criação de uma teoria política brasileira, dinâmica e autônoma, que buscava se adaptar às peculiaridades do país, em constante transformação, e dar 
subsídios a um desenvolvimento econômico que poderia enfim emancipar a sociedade, Guerreiro ingressa na vida partidária, se filiando ao PTB.

É importante salientar que o ingresso na vida partidária não apresenta um desvio na trajetória de Guerreiro Ramos. Pelo contrário, como nos mostram Azevêdo e Albernaz, "o seu adentramento na vida político-partidária foi justificado por ele em razão de seus propósitos intelectuais, antes que puramente políticos” (AZEVÊDO; ALBERNAZ, 2005, p. 5). Nesse sentido, há uma entrevista dada à época ao Diário da Tarde, citada no trabalho desses autores:

Nesses últimos anos, atingi o máximo de consciência possível do processo brasileiro, dentro do quadro acadêmico de professor. Neste momento, tenho a impressão de que me encontro nas condições de um debutante. De alguém que tem de vencer a inércia psicológica de 30 anos de professor para, sob o imperativo de melhor servir à coletividade, dar-lhe uma cobertura científica e conceitual mais operosa e mais eficaz. Essa nova equação que venho de adotar está me impondo uma participação mais profunda no jogo político do país e nos dramas dos interesses econômicos [...;] aceitei este posto partidário, entre outras coisas, porque estou convencido de que ele contribuirá para elevar o nível científico de minha produção sociológica (GUERREIRO RAMOS apud AZEVÊDO; ALBERNAZ, 2005, p. 5).

Naquele momento, ele via-se, em seus próprios termos, disposto a se tornar um "sociólogo em mangas de camisa". Assim, em 1962 foi candidato a deputado federal pelo PTB do então estado da Guanabara. Não obteve uma quantidade expressiva de votos, porém, suficiente para atingir a segunda suplência. Com o afastamento de Leonel Brizola da Câmara dos Deputados em agosto de 1963, Guerreiro Ramos assumiu a cadeira de deputado federal. Foi à tribuna 7I vezes, e apresentou cinco projetos de lei.

Versou sobre uma variada gama de assuntos, dos quais se destacam a defesa da reforma agrária, o papel e o significado da Organização das Nações Unidas (ONU) e o embate ideológico com a direita representada pela UDN e com a ala da esquerda representada pelo PCB. No período, o Brasil passava por um processo de democratização acelerada, com a ascensão do "povo" como categoria sociológica, que deveria ser transmitida ao plano político-institucional, como mencionado. Naquele momento, os partidos, como mostra Guerreiro, passavam por uma grave crise de representatividade. E é nessa crise que ele tenta influenciar no Congresso, muitas vezes em tom professoral, que não perde dos seus anos de magistério.

Ao analisar a atuação parlamentar de Guerreiro, percebemos que levou consigo sua teoria da sociedade brasileira para o Congresso, não se deixando dominar por uma política parlamentar vazia. Mostrou-se coerente com a missão do intelectual e da vanguarda política em operar as transformações necessárias ao desenvolvimento do país. Podemos verificar em sua atuação a influência das ideias que desenvolveu 


\section{Guerreiro Ramos nos aparece}

como um dos poucos exemplos

de nossa sociedade que se

posicionou como vanguarda

no pensamento social, e,

posteriormente, como vanguarda

na práxis política. Talvez nisso

esteja uma das razões do grande desinteresse em seus estudos nos dias de hoje

desde $A$ redução sociológica até suas obras políticas mais maduras e recentes. Nesse intuito, afirmou em plenário:

Sr. presidente, faço estas considerações porque considero que estamos vivendo uma série de ineditismos nos dias que passam. E é necessário que convoquemos toda a nossa lucidez para compreender, na sua exata significação, o ineditismo dos dias que estamos vivendo. Um dos pontos preliminares, ou um dos pontos básicos, uma tese fundamental do discurso que ora iniciamos, é o de que os fatos que assinalam os dias que estamos vivendo mostraram que estamos no limiar de um período novo de nossa história econômica, social e política. E é necessário compreender de um modo global e configurado em que consistem as características fundamentais desse novo período, a fim de que possamos melhor conduzi-lo, a fim de que sejamos agentes ativos do processo histórico do Brasil e não nos tornemos matéria bruta dos acontecimentos, não vivamos de episódio em episódio sem a habilitação para conduzi-los segundo as linhas mestras desse período novo que na minha opinião se está iniciando neste momento. Podemos dizer que nestes últimos anos tem sido tão escassa a consciência histórica dos círculos dirigentes deste país, que quase se poderia afirmar que neste período teríamos tido mais história natural do que história política propriamente (BRASIL, I963b, p. 8.32I).

Entre os principais temas levantados em plenário, Guerreiro versou sobre reforma agrária, profissionalização do serviço público, greves, soberania nacional dos programas econômicos, situação da formação do mercado interno brasileiro, trabalhismo e crise política internacional, entre outros assuntos. Podemos ver que Guerrei- 
ro, durante todo o breve momento em que foi deputado, esteve atento aos problemas nacionais, mesmo sem ignorar a conjuntura internacional, buscando dar subsídios à elevação do Brasil ao nível de potência democrática, a fim de melhorar a vida de seus cidadãos internamente e tornar o país relevante no jogo geopolítico mundial. Foi cassado com o golpe militar de 1964, perdendo seus direitos políticos e, posteriormente, sendo exilado nos EUA.

\section{CONSIDERACÕES FINAIS}

Este trabalho tentou resgatar o pensamento político de Guerreiro Ramos, caminhando juntamente com a construção e desenvolvimento da formação de sua perspectiva teórica. $\mathrm{O}$ autor nos apareceu em constante desenvolvimento, sendo impossível uma leitura fragmentada de sua obra. Por observação do processo político, buscamos demonstrar como, no curto período em que esteve representando o estado da Guanabara na Câmara dos Deputados, manteve-se fiel a seu pensamento e incitou os parlamentares a pensar os problemas brasileiros em termos nacionais.

Em uma conjuntura extremamente complicada, que viria a culminar no golpe militar de I $^{\circ}$ de abril de 1964 , Guerreiro pode se classificar no que San Tiago Dantas chamou de "esquerda positiva". E, se de um lado defendia as reformas de base como necessárias ao desenvolvimento nacional, de outro propunha sua feitura democraticamente, e não "na marra". Por isso, acabou muitas vezes por se isolar de uma esquerda radicalizada e inconsequente, bem como de uma direita entreguista e não nacionalista. Esse isolamento político nos pareceu ser um combustível para que Guerreiro Ramos não desistisse da missão que enxergava para si. O cientista social e o político não deveriam trabalhar para o próprio deleite, ou distantes da realidade. Em um momento crucial da história brasileira, o primeiro era convidado a teorizar, e o segundo, a agir. Guerreiro Ramos nos aparece como um dos poucos exemplos de nossa sociedade que se posicionou como vanguarda no pensamento social, e, posteriormente, como vanguarda na práxis política. Talvez nisso esteja uma das razões do grande desinteresse em seus estudos nos dias de hoje.

* Mestre e doutorando em Ciência Política pelo Instituto de Estudos Sociais e Políticos da Universidade do Estado do Rio de Janeiro (lesp-Uerj). Currículo Lattes: <http://lattes.cnpq.br/2541961101426785>

E-mail: angeloremedioneto@iesp.uerj.br

Texto recebido em 15 de maio de 2021; aprovado em 5 de julho de 2021. 
AZEVÊDO, Ariston; ALBERNAZ, Renata Ovenhausen. Alberto Guerreiro Ramos, um deputado. In: CONGRESSO BRASILEIRO DE SOCIOLOGIA, 12., 2005, Belo Horizonte. Anais... Sociedade Brasileira de Sociologia, 2005. Disponível em: <www.sbsociologia.com.br/portal/index.php?option=com_docman\&task=cat_view\&gid=54\&ltemid=171>. Acesso em: 5 jul. 2021.

BRASIL. Congresso Nacional. Diário do Congresso Nacional, Brasília, n. 155, 12 out. 1963a. Disponível em: <http://imagem.camara.gov.br/lmagem/d/pdf/DCD12OUT1963.pdf\#page=59>. Acesso em: 15 jul. 2021.

Congresso Nacional. Diário do Congresso Nacional, Brasília, n. 166, 29 out. 1963b. Disponível em: <http://imagem.camara.gov.br/Imagem/d/pdf/DCD26NOV1963.pdf\#page=54>. Acesso em: 15 jul. 2021.

Congresso Nacional. Diário do Congresso Nacional, Brasília, n. 172, 7 nov. 1963c. Suplemento. Disponível em: <http://imagem.camara.gov.br/lmagem/d/pdf/DCD07NOV1963SUP.pdf\#page=9>. Acesso em: 15 jul. 2021.

FILGUEIRAS, Fernando de Barros. Guerreiro Ramos, a redução sociológica e o imaginário pós-colonial. Caderno CRH, Salvador, v. 25, n. 65, p. 347-363, maio-ago. 2012.

GUERREIRO RAMOS, Alberto. A crise do poder no Brasil: problemas da revolução nacional brasileira. Rio de Janeiro: Zahar, 1961.

A redução sociológica. 2. ed. Rio de Janeiro: Editora da UFRJ, 1995a.

Cartilha brasileira do aprendiz de sociólogo: prefácio para uma sociologia nacional. Rio de Janeiro: Andes, 1954.

Introdução crítica à sociologia brasileira. 2. ed. Rio de Janeiro: Editora da UFRJ, 1995b.

Mito e verdade da revolução brasileira. Rio de Janeiro: Zahar, 1963.

O problema nacional do Brasil. Rio de Janeiro: Saga, 1960.

LYNCH, Christian Edward Cyril. Teoria pós-colonial e pensamento brasileiro na obra de Guerreiro Ramos:o pensamento sociológico. Caderno CRH, Salvador, v. 28, p. 27-45, jan.-abr. 2015.

MAIA, João Marcelo Ehlert. A sociologia periférica de Guerreiro Ramos. Caderno CRH, Salvador, v. 28, n. 73, p. 47-58, jan.-abr. 2015.

MOTTA, Luiz Eduardo. A política do Guerreiro: nacionalismo, revolução e socialismo no debate brasileiro nos anos 1960. Organizações \& Sociedade, v. 17, p. 85-101, 2010. 